\title{
The Jonas Scholars Program-Evaluation of a decade-long program to advance doctoral-prepared
}

\section{nurses}

\author{
Eileen J. Carter, $\mathrm{PhD}, \mathrm{RN}^{a, b}$, Wanda Montalvo, $\mathrm{PhD}, \mathrm{RN}, \mathrm{FAAN} \mathrm{N}^{\mathrm{c}, *}$, \\ Althea Hicks, EdD, MPH ${ }^{c}$, Jianfang Liu, PhD, MAS, BE ${ }^{d}$, \\ Kenrick D. Cato, PhD, RN, CPHIMS, FAAN ${ }^{a}$ \\ ${ }^{a}$ Columbia University School of Nursing, New York, NY \\ ${ }^{\mathrm{b}}$ New York-Presbyterian Hospital, New York, NY \\ Jonas Nursing and Veterans Healthcare, Columbia University School of Nursing, New York, NY \\ ${ }^{\mathrm{d} Q u a n t i t a t i v e ~ R e s e a r c h ~ i n ~ N u r s i n g, ~ C o l u m b i a ~ U n i v e r s i t y ~ S c h o o l ~ o f ~ N u r s i n g, ~ N e w ~ Y o r k, ~ N Y ~}$
}

\section{A R T I C L E I N F O}

Article history:

Received 15 August 2019

Received in revised form

13 December 2019

Accepted 2 January 2020

Keywords:

Doctoral education

Funding

Philanthropy

Nursing

\begin{abstract}
A B S T R A C T
Background: The Jonas Scholars Program of Jonas Nursing \& Veterans Healthcare aims to advance the pipeline of doctoral-prepared, research-focused, and practice-focused faculty via student financial support and leadership training.

Purpose: Program evaluation of the Jonas Scholars Program. We describe the reach of the program over time, scholar characteristics, and report on graduated scholars that are currently employed in faculty and clinical positions.

Method: Retrospective analysis of administrative records from the Jonas Scholars Program spanning 2008 to 2016.

Findings: The Jonas Scholars Program has grown substantially since its inception. From 2008 to 2016, a total of 1,032 doctoral students at 174 universities across the United States have received financial support through the program. Scholars have a mean age of 38 and nearly two-thirds are enrolled in a research-focused $\mathrm{PhD}$ program. Most graduated scholars for which data are available are primarily faculty in nursing schools 185 (30.7\%), providing direct patient care $171(28.4 \%)$, or conducting research 118 (19.8\%).

Discussion: The Jonas Scholars Program supports the pipeline of a younger generation of doctoral-prepared nurses that are faculty in schools of nursing, providing direct patient care and conducting research.

Cite this article: Carter, E.J., Montalvo, W., Hicks, A., Liu, J., \& Cato, K.D. (2020, xxx). The Jonas Scholars Program-Evaluation of a decade-long program to advance doctoral-prepared nurses. Nurs Outlook, 00 (00), 1-6. https://doi.org/10.1016/j.outlook.2020.01.003.
\end{abstract}

Declaration of Competing Interest: Dr. Carter was a former Jonas Scholar. Dr. Cato was a former Jonas Scholar and Jonas Veterans Scholar. Dr. Hicks is the Grant and Programs Manager of Jonas Nursing and Veterans Healthcare. Dr. Montalvo was a former Jonas Scholar and is the Executive Director Jonas Nursing and Veterans Healthcare.

${ }^{*}$ Corresponding author: Wanda Montalvo, Jonas Nursing and Veterans Healthcare, Columbia University School of Nursing, 560 W. 168 th St. New York, NY 10032.

E-mail address: wm2288@cumc.columbia.edu (W. Montalvo).

0029-6554/\$ -see front matter @ 2020 The Authors. Published by Elsevier Inc. This is an open access article under the CC BY-NC-ND license. (http://creativecommons.org/licenses/by-nc-nd/4.0/) 


\section{Background}

In 2006, philanthropists Barbara and Donald Jonas founded Jonas Nursing and Veterans Healthcare (JNVH). Formerly known as the Jonas Center for Nursing Excellence, JNVH is among one of the first philanthropic organization in the United States that aims to improve health care through the advancement of the nursing profession (Jonas Nursing and Veterans Healthcare, 2017, 2018). Barbara Jonas, a retired social worker, and Donald Jonas, a retired retail executive, were avid art collectors. In a desire to increase their philanthropic efforts, Barbara and Donald Jonas auctioned several of their expressionist art pieces for \$44 million (Jonas Nursing and Veterans Healthcare, 2018). Auction proceeds have laid the foundation for a series of initiatives whose purpose is to improve health care, including the Jonas Scholars Program.

The Jonas Scholars Program of JNVH aims to curtail the mounting shortage of doctoral-prepared nurses, which threatens the health care communities' ability to meet the growing health needs of the nation and directly responds to the Institute of Medicine's "Future of Nursing" report, which recommends doubling the number of nurses with a doctorate by 2020 (Institute of Medicine Committee on the Robert Wood Johnson Foundation Initiative on the Future of Nursing, 2011). In its 2008 annual survey of U.S. nursing schools, the American Association of Colleges of Nursing (AACN) found that among 449 surveyed schools, 282 faculty positions were vacant for an overall vacancy rate of $8 \%$ and $155(55 \%)$ of vacancies were at the doctoral level (American Association of Colleges of Nursing, 2018). A recent survey conducted by the AACN demonstrates the persistence of the faculty shortage among doctoral-prepared faculty. Among 871 surveyed schools, 1,715 faculty positions were vacant for an overall vacancy rate of $8 \%$. Among vacant faculty positions, a doctorate is required in $56 \%(N=962)$ and preferred in $35 \%$ of positions $(N=593)$ ( $\mathrm{Li}$ et al., 2019). Thus, indicating little progress has been made in curtailing the faculty shortage among doctoral-prepared faculty in the past decade.

The nursing faculty shortage is a major contributor to the nonacceptance of well-qualified applicants to schools of nursing (American Association of Colleges of Nursing, 2001, 2017). In the AACN's 2016 to 2017 Annual Evaluation of Enrollment and Graduations in Baccalaureate and Graduate Nursing Programs, it was found that more than 64,000 applicants were turned away from nursing programs due to a lack of resources, including a dearth of nurse faculty, clinical sites, and finance constraints (American Association of Colleges of Nursing, 2017). Similarly, the National League of Nursing's biennial survey of nursing schools found that $27 \%$ of respondent schools reported a lack of faculty as the principal reason for a lack of program capacity expansion (National League for Nursing, 2018). The inability of schools of nursing to accept qualified applicants into programs is especially alarming as health care reform is in a state of uncertainty and as nurse employment is expected to increase by $16 \%$ between 2014 and 2024 (US Bureau of Labor Statistics, 2016).

The anticipated retirement of numerous doctoral nursing faculty underscores the need for an increased pipeline of nurses prepared at the doctoral level (Fang \& Kesten, 2017). Currently, the average age of doctoral faculty that hold the title of professor, associate professor, and assistant professor are 62, 58, and 51, respectively (American Association of Colleges of Nursing, 2017), indicating that a substantial portion of tenure and seasoned current doctoral faculty are approaching retirement. Fang \& Kesten (2017) estimate that the total number of nursing faculty that retire in the next 10 years will equal approximately one-third of total nursing faculty in 2015, indicating that the need to address the current nursing faculty shortage has become more dire.

The Jonas Scholars Program, led by JNVH is housed at Columbia University School of Nursing, as the signature program of Jonas Philanthropies (http://jonasphilanthro pies.org), and is a partnership between nonprofit organizations, foundations, private donors, and academic institutions. The overarching aim of the program is to support the doctoral education of individual nursing students in their ability to address our nation's most pressing health needs through research, education, service, and/or leadership. Postdoctoral education, it is envisioned that those selected as Jonas Scholars may become faculty in academic institutions to educate the next generation of nursing scholars and identify new treatment and prevention modalities via research; provide direct patient care in which they use their clinical expertise to optimize the health of communities and individuals; and enter leadership positions in which they influence system changes to improve the health of individuals and populations.

Schools of nursing that have existing partnerships with JNVH select individual doctoral students to be a Jonas Scholar. The JNVH provides schools with selection criteria for Jonas Scholars, which are influenced by funding partners' predefined priority areas (e.g., multiple chronic conditions, veteran health, palliative care, mental health). Students selected as Jonas Scholars benefit from financial support that helps to alleviate financial stressors characteristic of doctoral-level education and leadership training that parallels the support provided by schools. Notably, students selfselect their areas of interest and their advisement at the school facilitates these interests. Six students entered the first cohort of Jonas Scholars between 2008 and 2010, and received full tuition support for their $\mathrm{PhD}$ program. The financial model was updated in 2010, in which Jonas Scholars received financial support during their 2-year tenure as a Jonas Scholar and this financial support was matched by the scholars' school. In addition to monetary assistance, Jonas Scholars obtain leadership training via their participation in a Jonas Leadership Project and by attending the bi-Annual Jonas Scholars Conference in Washington, DC, where scholars are exposed to diverse thought (e. g., experts in policy, organizational leadership, interprofessional collaboration). 


\section{Purpose}

To the best of our knowledge, no formal program evaluation has been conducted of the Jonas Scholars Program. We conducted a program evaluation of the Jonas Scholars Program to describe the growth of the Jonas Scholars Program over time and report on the positions of Jonas Scholars upon completion of doctoral education.

\section{Methods}

We conducted a retrospective analysis of Jonas Scholars Program administrative data available from JNVH. These data include the interim and final reports submitted by Jonas Scholars as well as administrative records that are maintained by JNVH for record keeping. We used descriptive statistics to analyze data. Means and standard deviations were used to describe continuous data; frequencies and proportions were used to describe categorical data. To compare the demographics of scholars who pursued their PhD and DNP, we used ANOVA and chi-square, as indicated. Of note, our description of demographics was limited to years 2014 to 2018 (Jonas Scholar Cohorts IV and V) as dictated by available data. Similarly, our analysis of Jonas Scholar's employment role was limited to 2008 to 2016 (Jonas Scholar Cohorts I, II, III, and IV), as final Jonas Scholar reports were only available from these cohorts at the time of data analysis. This study was approved by Columbia University Institutional Review Board.

\section{Findings}

\section{Jonas Scholar Program Growth Over Time}

From 2008 to 2018, a total of 1,032 doctoral nursing students were selected as Jonas Scholars and entered 1 of 5 existing Jonas Scholar program cohorts. Among Jonas Scholars, 662 (64\%) were enrolled in a $\mathrm{PhD}$ program, 358 (35\%) were enrolled in a DNP program, and $12(1 \%)$ were enrolled in a DNSc or EdD program (Figure 1). The inaugural cohort, Jonas Scholars 2008 to 2010 included six doctoral nursing students from five schools; Jonas Scholars 2010 to 2012 consisted of 55 doctoral nursing students from 23 schools; Jonas Scholars 2012 to 2014 comprised 208 doctoral nursing students from 89 schools; Jonas Scholars 2014 to 2016 included 338 doctoral nursing students from 128 schools; and Jonas Scholars 2016 to 2018 consisted of 425 doctoral nursing students from 139 schools. A complete list of schools of nursing that have received Jonas Scholar financial support is provided in the Appendix.

The geographic distribution of Jonas Scholars and their school of nursing are depicted in Figure 2. The volume of Jonas Scholars per state ranged from a minimum of 2 to a maximum of 127. To date, the states with the greatest number of Jonas Scholars are: New York (127), California (96), and Pennsylvania (72). The states with the lowest number of Jonas Scholars are: Alaska, Montana, and New Hampshire, each with less than 2 scholars. Per cohort, the geographic distribution of Jonas Scholars across states is as follows: 2008 to 2010: three states, 2010 to 2012: 17 states, 2012 to 2014: 45 states, and 2014 to 2016: 47 states.

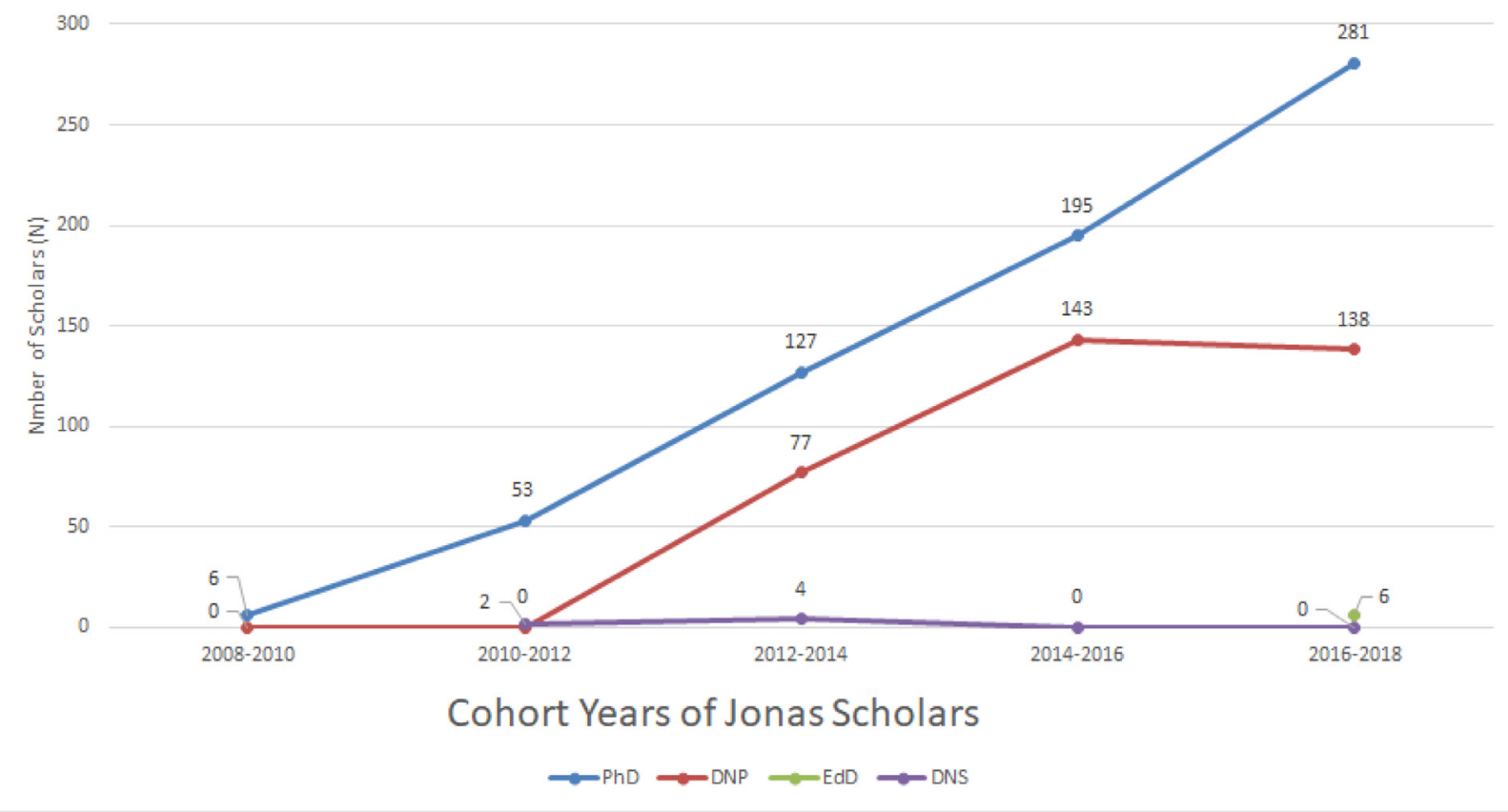

Figure 1-Growth of Jonas Scholars Program from 2008 to 2018. 


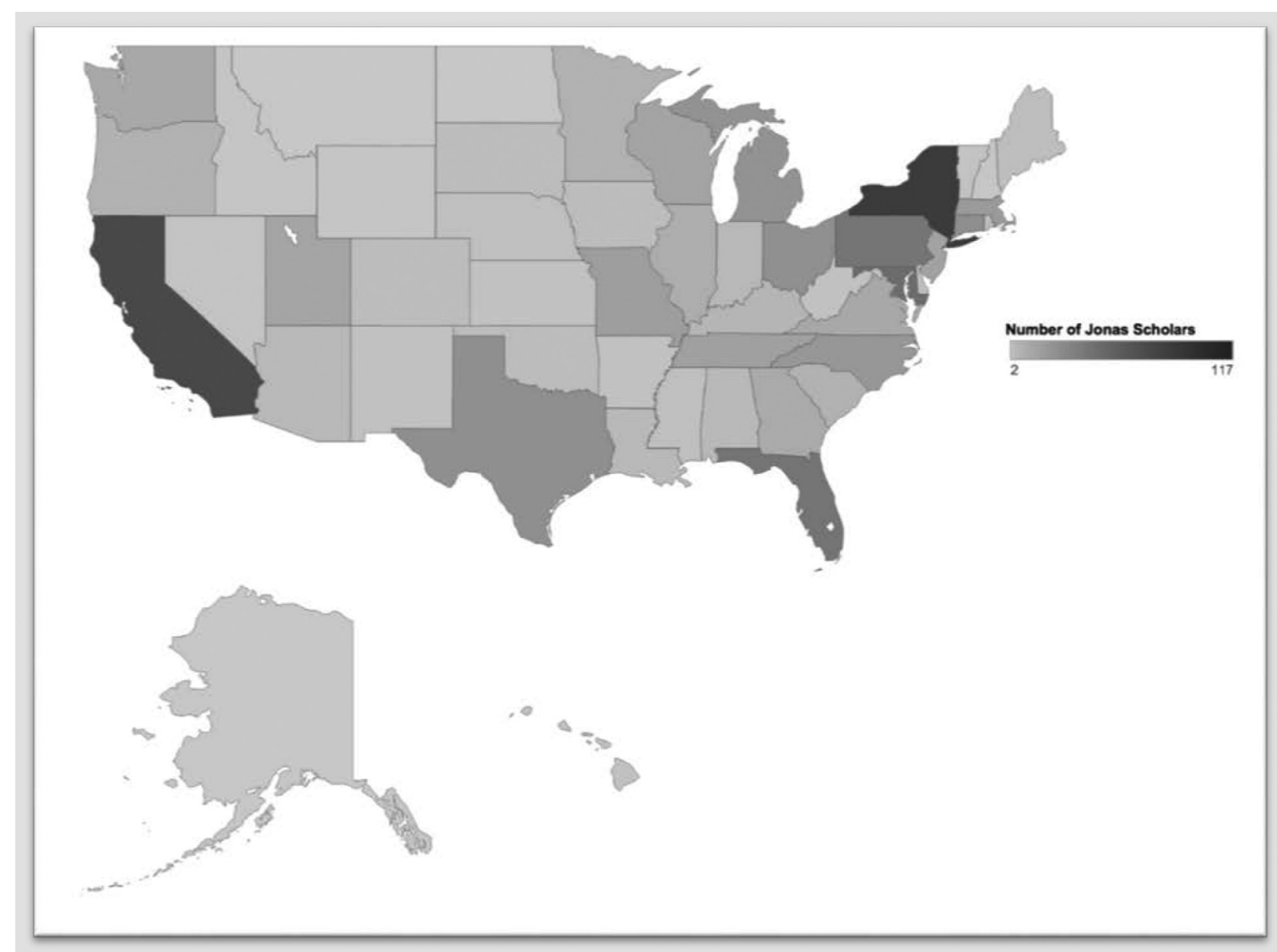

Figure 2-Geographic distribution of Jonas Scholars.

\section{Jonas Scholar Demographics}

Among Jonas Scholars for which demographic information was available, 487 (63\%) were white and 673 (96\%) non-Hispanic. The mean age of scholars was 38 $(S D=10)$. No significant differences were noted between median age, race, and ethnicity between Jonas Scholars pursuing their PhD or DNP (Table 1).

\section{Jonas Scholar Outcomes}

Among Jonas Scholars from 2008 who graduated, Jonas Scholars were employed as: faculty 189 (30.7\%), clinicians 172 (28.4\%), and researchers 118 (19.8\%). The remainder graduated scholars were working in administration, government, consulting, and the military.

\section{Discussion}

In our decade-long evaluation of the Jonas Scholars Program, we found that the program grew extensively in number and in reach since its inception and that the vast majority of graduated, doctoral-prepared scholars for which data are available hold clinical, faculty, and researcher positions, thus indicating the
Jonas Scholars Program supports the pipeline of doctoral-prepared nurses that are actively engaged in education, service, and research. Jonas Scholars have a mean age of 38 , which likely reflects novel recruitment efforts undertaken by Schools of Nursing and a growing interest among nurses to pursue doctoral education at a younger age. We also found nearly $63 \%$ of Jonas Scholars were white and the remaining 37\% were minority, which is consistent with recent reports of the race and ethnicity of nursing students enrolled in research-focused doctorate programs (67\% white, remaining 33\% minority) (American Association of Colleges of Nursing, 2019).

Our evaluation identified noteworthy efforts taken by the Jonas Scholars Program to address the stagnant growth in PhD program enrollment. Between 2004 and 2013, PhD enrollment at schools of nursing increased by $49 \%$ (from 3,439 to 5,124 ) while DNP program enrollment increased 85-fold (from approximately 170 to 14,699) over the same time frame (Geraldine, Breslin, Kirschling, \& Rosseter, 2014). Despite this, we found nearly two-thirds of Jonas Scholar funding was allocated to those in PhD programs. In addition, from 2014 to 2018, the Jonas Scholars Program substantially increased their level of support among scholars pursuing a $\mathrm{PhD}$, while their level of support among scholars pursuing a DNP remained consistent (Figure 2), thus 
Table 1-Jonas Scholar Demographics From Cohorts 2014 to 2018

\begin{tabular}{|c|c|c|c|}
\hline & $\begin{array}{l}\text { All Scholars* } \\
N=763\end{array}$ & $\begin{array}{l}\mathrm{PhD} / \mathrm{EdD} \\
482 \text { (62.39\%) }\end{array}$ & $\begin{array}{l}\text { DNP } \\
281(36.83 \%)\end{array}$ \\
\hline $\begin{array}{l}\text { Age, mean } \\
\text { (SD) }\end{array}$ & $37.70(9.62)$ & $37.90(9.23)$ & $37.48(10.21)$ \\
\hline \multicolumn{4}{|l|}{ Gender } \\
\hline Males & 89 (11.66) & 50 (10.37) & 39 (13.88) \\
\hline Females & $674(88.33)$ & 432 (89.62) & 242 (86.12) \\
\hline \multicolumn{4}{|c|}{ Race \& ethnicity } \\
\hline White & $487(63.17)$ & $313(69.89)$ & $174(22.80)$ \\
\hline $\begin{array}{l}\text { Hispanic or } \\
\text { Latino }\end{array}$ & $31(4.06)$ & $18(2.36)$ & $13(1.70)$ \\
\hline $\begin{array}{l}\text { Asian or } \\
\text { Pacific } \\
\text { Islander }\end{array}$ & $56(7.34)$ & $31(4.06)$ & $25(3.28)$ \\
\hline $\begin{array}{l}\text { Black or } \\
\text { African } \\
\text { American }\end{array}$ & $104(13.50)$ & 71 (9.17) & $33(4.33)$ \\
\hline $\begin{array}{l}\text { American } \\
\text { Indian or } \\
\text { Alaskan } \\
\text { Native }\end{array}$ & $6(0.79)$ & $4(0.52)$ & $2(0.27)$ \\
\hline $\begin{array}{l}\text { Two or } \\
\text { more races }\end{array}$ & $13(1.70)$ & $8(1.05)$ & $5(0.66)$ \\
\hline Other & $66(8.65)$ & $37(4.85)$ & $29(3.80)$ \\
\hline
\end{tabular}

Table 2 - Position of Graduated Jonas Scholars Cohorts 2008 to 2016

\begin{tabular}{|c|c|c|c|}
\hline & $\begin{array}{l}\text { Overall } \\
(n=607) \\
N(\%)\end{array}$ & $\begin{array}{l}\text { PhD } \\
(n=381) \\
N(\%)\end{array}$ & $\begin{array}{l}\text { DNP/DNS } \\
(n=226) \\
N(\%)\end{array}$ \\
\hline Clinical & $172(28.4)$ & 67 (17.5) & 105 (46.7) \\
\hline Faculty & 189 (30.7) & $153(40.3)$ & $36(14.7)$ \\
\hline Research & $118(19.8)$ & 95 (24.9) & $23(11.1)$ \\
\hline Administration & $50(8.1)$ & $29(7.4)$ & $21(9.3)$ \\
\hline Government & $1(0.2)$ & $0(0)$ & $1(0.4)$ \\
\hline Consulting & $5(0.8))$ & $4(1.1)$ & $1(0.4)$ \\
\hline Military & $72(12.0)$ & $33(8.8)$ & 39 (17.3) \\
\hline
\end{tabular}

indicating a particular commitment among the Jonas Scholars Program to research-focused education.

Our analysis found that the Jonas Scholars Program expanded considerably since its inception 10 years ago. Specifically, from the initial Jonas Scholars Program cohort in 2008 to its most recent cohort in 2016, the number of individuals named a Jonas Scholar by cohort increased nearly 70 -fold. The approaches used by JNVH, including collaboration with external grant funders; schools of nursing; as well as foundations and nonprofits, likely supported the Jonas Scholar Program growth and success. In particular, the financial support provided by JNVH likely helped to address well-known budget constraints that prevent schools' from accepting qualified nursing applicants into their programs (American Association of Colleges of Nursing, 2018; National League for Nursing, 2018). A unique aspect of the Jonas Scholars Program is that $100 \%$ of contributions directly support scholarships and leadership development among selected
Jonas Scholars. Efforts to address the growing nurse faculty shortage have been categorized as advocacy, educational partnerships, academic innovation, and external funding (Allan \& Aldebron, 2008). While the Jonas Scholars Program funding has largely consisted of public and private partnerships, private donors and foundations, it also relied upon educational partnerships and academic innovation to grow and sustain program efforts. Such a multipronged approach is likely needed to sustain and scale efforts to address the nurse faculty shortage.

The Jonas Scholar Program is one of several philanthropic-led initiatives to influence innovation at schools of nursing. Additional philanthropic-led initiatives include the Future of Nursing Scholars program, developed by the Robert Wood Johnson Foundation, which supports the completion of a PhD in 3 years of full-time study (http://futureofnursingscholars.org), as well as the Rita and Alex Hillman Foundation Scholar Program (http://www.rahf.org/grant-programs/scholars), which supports seamless BSN to PhD education. A majority of studies to evaluate the impact of philanthropic efforts have found long-term benefits, including increases in the number of doctoral-prepared nurses working in academia and service, high levels of productivity among program graduates, and increased visibility and standing of academic institutions (Hickey et al., 2014; McBride et al., 2017). While the advantages of such programs are clear, program sustainability remains a challenge given the financial costs, mentorship capacity, and administrative support required of programs, as well as changes in organizational foci.

The Jonas Scholars Program has been in existence for 10 years and committed an additional 10 years to fund scholarships, fellowships, and leadership development. The JNVH has developed new programs to address pressing concerns by supporting Jonas Policy Scholars at the American Academy of Nursing, a new series of SigmaJonas research grants, networking events, and educational webinars. Hence, there remains a need for ongoing monitoring of program need and assessment of longterm outcomes of the contributions Jonas Scholars to research, education, clinical practice, veterans' health care, policy, and leadership roles to ensure that programs remain germane over time and effectively support nurses' pursuit of pre- and postdoctoral education. As part of future research, the JNVH is tracking data to assess the long-term impact of the Jonas Scholar Program (i.e., publications, awards, policy presentations, nurse-led research).

\section{Limitations}

Our program evaluation of the Jonas Scholars Program has two primary limitations. First, our analysis relied on cross-sectional data, which cannot establish longitudinal trends. While we were able to determine the location of many Jonas Scholars' employment at the time of their completion of the Jonas Scholars Program, 
prospective studies are needed to determine the longterm contributions of Jonas Scholars over time for example, years worked as clinical faculty, years worked in academic setting, publication records, leadership roles, etc. Second, our analysis was a retrospective review of existing Jonas Scholars Program administrative data and as such, we were only able to report on data which were available and unable to compare outcomes between Jonas Scholars and non-Jonas Scholars.

\section{Conclusion}

The Jonas Scholars Program facilitates the pipeline of doctoral prepared nurses in faculty, clinical, and research positions. Additional research is needed to determine the impact of the Jonas Scholars Program over time.

\section{Acknowledgments}

The authors thank Donald Jonas, Barbara Jonas, and Jonas Nursing and Veterans Healthcare for their steadfast commitment to the advancement of the nursing profession. The authors thank previous and current Jonas staff: Darlene Curley MS, RN FAAN, Kelly Mahoney MPA, Eliza Bromfield, and Maggie Gelwix for their assistance obtaining administrative data available from Jonas Nursing and Veterans Healthcare.

\section{Supplementary materials}

Supplementary material associated with this article can be found in the online version at doi:10.1016/j.out look.2020.01.003.

\section{R E F E R E N C E}

Allan, J. D., \& Aldebron, J. (2008). A systematic assessment of strategies to address the nursing faculty shortage, U.S. Nursing Outlook, 56(6), 286-297, doi:10.1016/j.outlook.2008.09.006.

American Association of Colleges of Nursing. (2001). Annual state of the schools. Retrieved from: http://www. aacn.nche.edu/publications/annual-reports/AR2001. pdf.
American Association of Colleges of Nursing. (2017) Nursing faculty shortage fact sheet. http://www.aacnnurs ing.org/portals/42/news/factsheets/faculty-shortagefactsheet-2017.pdf.

American Association of Colleges of Nursing. (2018). Research and data center. Annual Surveys. Retrieved from: http://www.aacnnursing.org/News-Informa tion/Research-Data-Center/Annual-Surveys.

American Association of Colleges of Nursing. (2019). 10 years of race/ethnicity data available online. Washington, DC Retrieved from: https://www.aacnnursing.org/ Portals/42/News/Surveys-Data/EthnicityTbl.pdf

Fang, D., \& Kesten, K. (2017). Retirements and succession of nursing faculty in 2016-2025. Nursing Outlook, doi:10.1016/j.outlook.2017.03.003.

Geraldine, B., Breslin, E. T., Kirschling, J. K., \& Rosseter, R. J. (2014). PhD or DNP: Planning for doctoral nursing education. Nursing Science Quarterly, 27(4), 296-301, doi:10.1177/0894318414546415.

Hickey, K. T., Hodges, E. A., Thomas, T. L., Coffman, M. J., Taylor-Piliae, R. E., Johnson-Mallard, V. M., ..., \& Casida, J. M. (2014). Initial evaluation of the Robert Wood Johnson Foundation Nurse Faculty Scholars program. Nursing Outlook, 62(6), 394-401, doi:10.1016/j.outlook.2014.06.004.

Institute of Medicine Committee on the Robert Wood Johnson Foundation Initiative on the Future of Nursing, a. t. I. o. M.. (2011). The future of nursing: Leading change, advancing health. Washington DC: National Academies Press (US) Copyright 2011 by the National Academy of Sciences. All rights reserved.

Jonas Nursing and Veterans Healthcare. (2017). Our mission. Retrieved from: http://jonasphilanthropies.org/ nursing-and-veterans-healthcare/.

Jonas Nursing and Veterans Healthcare. (2018). Barbara and Donald Jonas family fund. Retrieved from: http://jona sphilanthropies.org/jonas-family-fund-appointslendri-purcell-vice-president-environmental-healthyouth-development-programming/.

Li, Y., Turinetti, M., \& Fang, D. (2019). Special survey on vacant faculty positions for academic year, 2018-2019. Washington, DC Retrieved from: https://www.aacn nursing.org/Portals/42/News/Surveys-Data/Vacancy18. pdf.

McBride, A. B., Campbell, J., Barr, T., Duffy, J., Haozous, E., Mallow, J., ..., \& Theeke, L. (2017). The impact of the nurse faculty scholars program on schools of nursing. Nursing Outlook, 65(3), 327-335, doi:10.1016/j.outlook.2017.01.013.

National League for Nursing. (2018). Biennial survey of schools for nursing, academic year, 2015-2016. Retrieved from: http://www.nln.org/newsroom/nursing-educa tion-statistics/biennial-survey-of-schools-of-nursingacademic-year-2015-2016.

US Bureau of Labor Statistics. (2016). Occupational outlook handbook. Retrieved from: https://www.bls.gov/ooh/ healthcare/registered-nurses.htm. 